\section{Cureus}

Received 10/01/2015

Review began 10/01/2015

Review ended 11/30/2015

Published 12/11/2015

\section{(c) Copyright 2015}

Duimering et al. This is an open access article distributed under the terms of the Creative Commons Attribution License CC-BY 3.0., which permits unrestricted use, distribution, and reproduction in any medium, provided the original author and source are credited.

\title{
SBRT Treatment of Metachronous Small- Cell and Non-Small-Cell Lung Carcinomas in a Patient with Severe COPD
}

Adele Duimering ${ }^{1}$, Zsolt Gabos ${ }^{1}$, Brock Debenham ${ }^{2}$

1. Radiation Oncology, Cross Cancer Center, University of Alberta 2. Radiation Oncology, Cross Cancer Center, University of Alberta, Edmonton, CAN

$\square$ Corresponding author: Adele Duimering, adeleduimering@gmail.com Disclosures can be found in Additional Information at the end of the article

\section{Abstract}

Stereotactic body radiotherapy (SBRT) has not been widely employed in the treatment of limited-stage (LS) small-cell lung cancer (SCLC), although SBRT finds particular utility in patients medically unfit to undergo surgical resection or radiotherapy with conventional fields. The authors present the case of a 61-year-old female smoker with severe chronic obstructive pulmonary disease (COPD), diagnosed incidentally with LS-SCLC. Concurrent chemoradiotherapy was contraindicated by her poor pulmonary function, and she was treated radically with four cycles of cisplatin and etoposide chemotherapy. This was followed by prophylactic cranial irradiation and consolidative SBRT (48 Gy in 4 fractions) to the residual tumour, which achieved a complete clinical response. Fifteen months following the patient's initial diagnosis, a metachronous Stage IA contralateral non-small cell lung cancer (NSCLC) was incidentally diagnosed and was treated with SBRT (48 Gy in 4 fractions). Although studies have established that the incidence of a second lung cancer is higher in patients with previous SCLC, this case is unique in that both primaries were treated with SBRT.

Categories: Radiation Oncology, Oncology

Keywords: small cell lung cancer, non-small cell lung carcinoma, copd, radiotherapy, stereotactic body radiotherapy

\section{Introduction}

The standard treatment of LS-SCLC in Canada consists of radical combined chemoradiotherapy: four cycles of cisplatin and etoposide, concurrent with thoracic irradiation (40 Gy in 15 fractions to 50 Gy in 25 fractions; or the Turrisi Regimen of 45 Gy in 30 fractions, dosed twice daily). Although the benefits of this concurrent thoracic radiotherapy in improving local control and overall survival were recognized a quarter-century ago, no large studies have compared conventionally fractionated external beam radiotherapy to SBRT in SCLC patients [1].

Fit LS-SCLC patients who lack evidence of nodal involvement or distant metastases may be considered for primary surgical resection, followed by chemotherapy [2]. Patients who have achieved at least disease stability after initial chemoradiotherapy or surgery and chemotherapy are offered prophylactic cranial irradiation (25 Gy in 10 fractions).

Patients surviving SCLC have a $2-13 \%$ per year risk of developing a second primary lung cancer, a 7- to 16-fold higher relative risk than a similar North American population [3]. The predominant histology of the second primary in this population is squamous cell carcinoma [3].

How to cite this article

Duimering A, Gabos Z, Debenham B (December 11, 2015) SBRT Treatment of Metachronous Small-Cell and Non-Small-Cell Lung Carcinomas in a Patient with Severe COPD. Cureus 7(12): e400. DOI $10.7759 /$ cureus. 400 
Stage I NSCLC is primarily managed by surgical resection, which achieves a locoregional control rate of $90 \%$ and five-year overall survival rates of 50-70\% [4]. In medically inoperable patients treated with primary radiotherapy, these locoregional control and five-year overall survival rates drop dramatically to 30-70\% and $15-30 \%$, respectively. While the overall survival difference may be attributed, in part, to poorer performance statuses of those unfit for surgery, the difference in local control raises the question of whether sufficiently high radiation doses are being prescribed [5]. Dose-limiting toxicities may be avoided by replacing conventionally fractionated radiotherapy with SBRT, thereby permitting higher per fraction radiation doses to be delivered. SBRT has been demonstrated to achieve similar rates of local control to surgical resection and, as such, is a reasonable first-line treatment for medically inoperable Stage I NSCLC that "may even challenge surgery in operable instances" [6-7].

\section{Case Presentation}

A 61-year-old female 50-pack-year smoker with severe COPD, advanced emphysema, chronic hypoxia on home oxygen secondary polycythemia, non-insulin-dependent diabetes mellitus, hypertension, dyslipidemia, and a stable, untreated renal cell carcinoma presented with an incidental finding of a left-upper-lobe (LUL) nodule on a chest x-ray performed during a COPD exacerbation. Apart from the chronic dyspnea from her underlying lung disease, the patient was asymptomatic with good functional capacity (Eastern Cooperative Oncology Group score 1). Physical exam was unremarkable. Signed informed patient consent was obtained.

Further imaging characterized an apical-posterior spiculated noncalcified $1.7 \mathrm{~cm}$ FDG-avid LUL pulmonary nodule, with no evidence of nodal involvement or metastatic disease (Figure $1 \mathrm{~A}$ ). Despite initial benign bronchoscopic LUL washing and brushing cytology, fine needle aspiration (FNA) biopsy of the mass demonstrated small-cell carcinoma (cT1a, cN0, cM0, Stage IA).

Given her poor pulmonary function (FEV1 of 0.39 pre-bronchodilator and 0.5 postbronchodilator, DLCO of $37 \%$ predicted), the patient was deemed not to be a candidate for combined chemoradiotherapy. Chemotherapy proceeded with the standard regimen of four cycles of cisplatin and etoposide. CT performed two weeks following chemotherapy completion demonstrated only partial response of the primary lesion, and the patient was offered adjuvant radical irradiation for the residual LUL tumour. An SBRT technique was selected to minimize pulmonary toxicity. Starting eight weeks following the last cycle of chemotherapy, $48 \mathrm{~Gy}$, prescribed to $95 \%$ of the PTV, were delivered in four fractions over two weeks by dynamic conformal arcs. Prophylactic cranial irradiation (25 Gy in 10 fractions) was also administered. The patient tolerated this treatment well and interval post-treatment imaging has demonstrated a sustained complete response.

Fifteen months after her initial diagnosis, the patient presented with a COPD exacerbation and hyponatremia. A CT scan revealed a new $2 \mathrm{~cm}$ peripheral right-upper-lobe (RUL) pulmonary nodule with FNA cytology demonstrating atypical epithelial cells, suspicious for NSCLC (not further histologically characterizable, given the limited FNA sample; cT1a, cN0, cM0, Stage IA) (Figure 1B). A right middle lobe collapse was noted and was ascribed to mucus bronchial plugging secondary to the patient's underlying lung disease, rather than malignant obstruction. 


\section{Cureus}

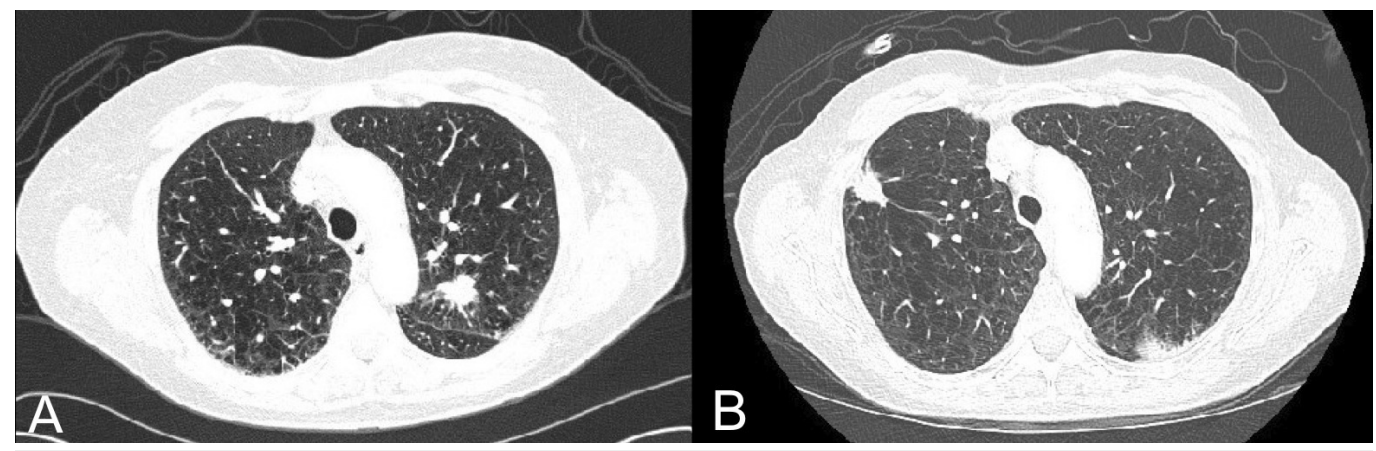

FIGURE 1: Pre-treatment CT images of (A) LUL LS-SCLC and (B) RUL Stage IA NSCLC.

The RUL NSCLC was treated with SBRT (48 Gy in four fractions), which the patient tolerated well (Figures 2-3). Post-treatment imaging is pending to assess disease response.

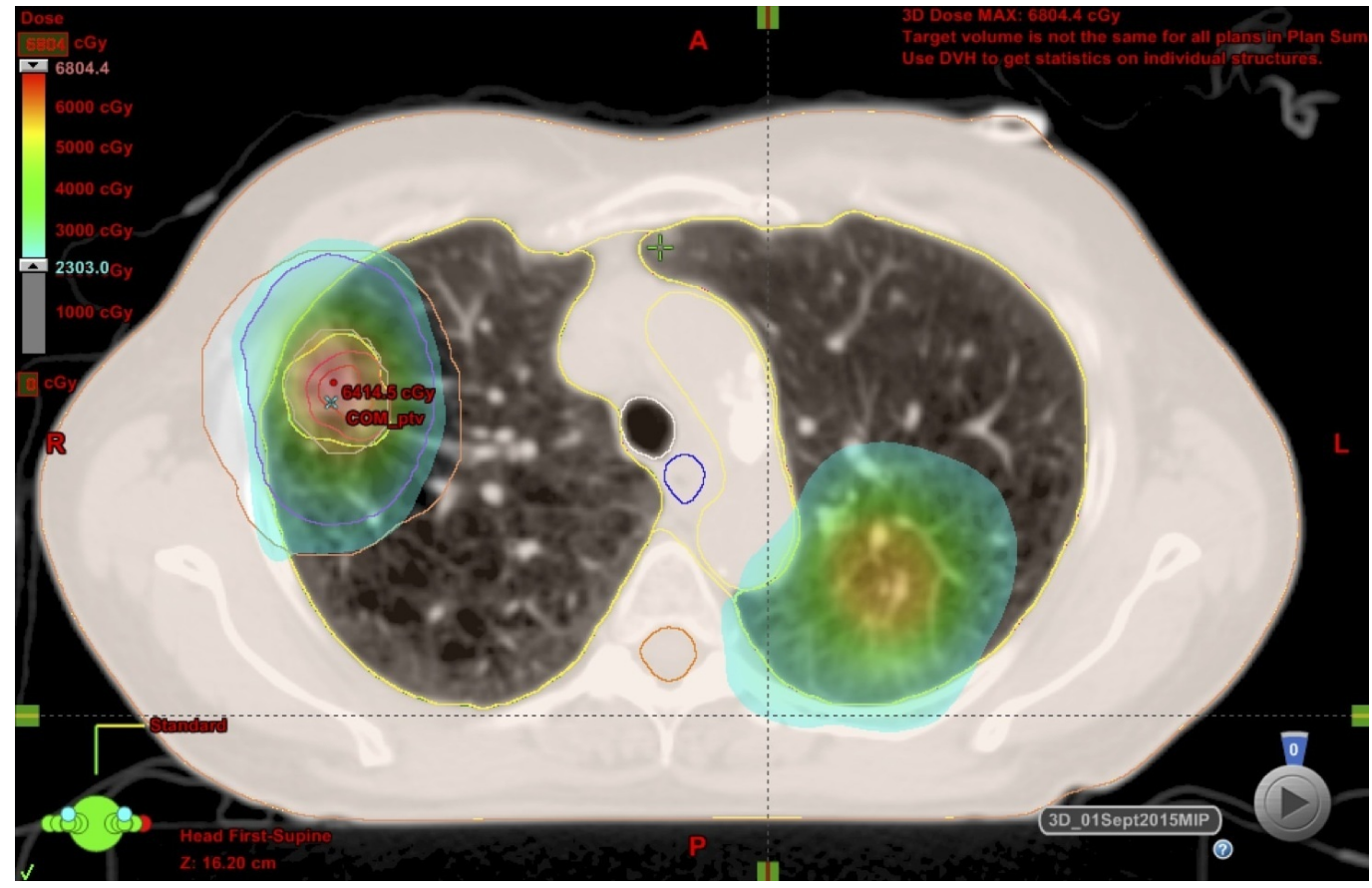

FIGURE 2: SBRT dose distributions: $48 \mathrm{~Gy}$, prescribed to $95 \%$ of the PTV, delivered in four fractions over two weeks, by dynamic conformal arcs. 


\section{Cureus}

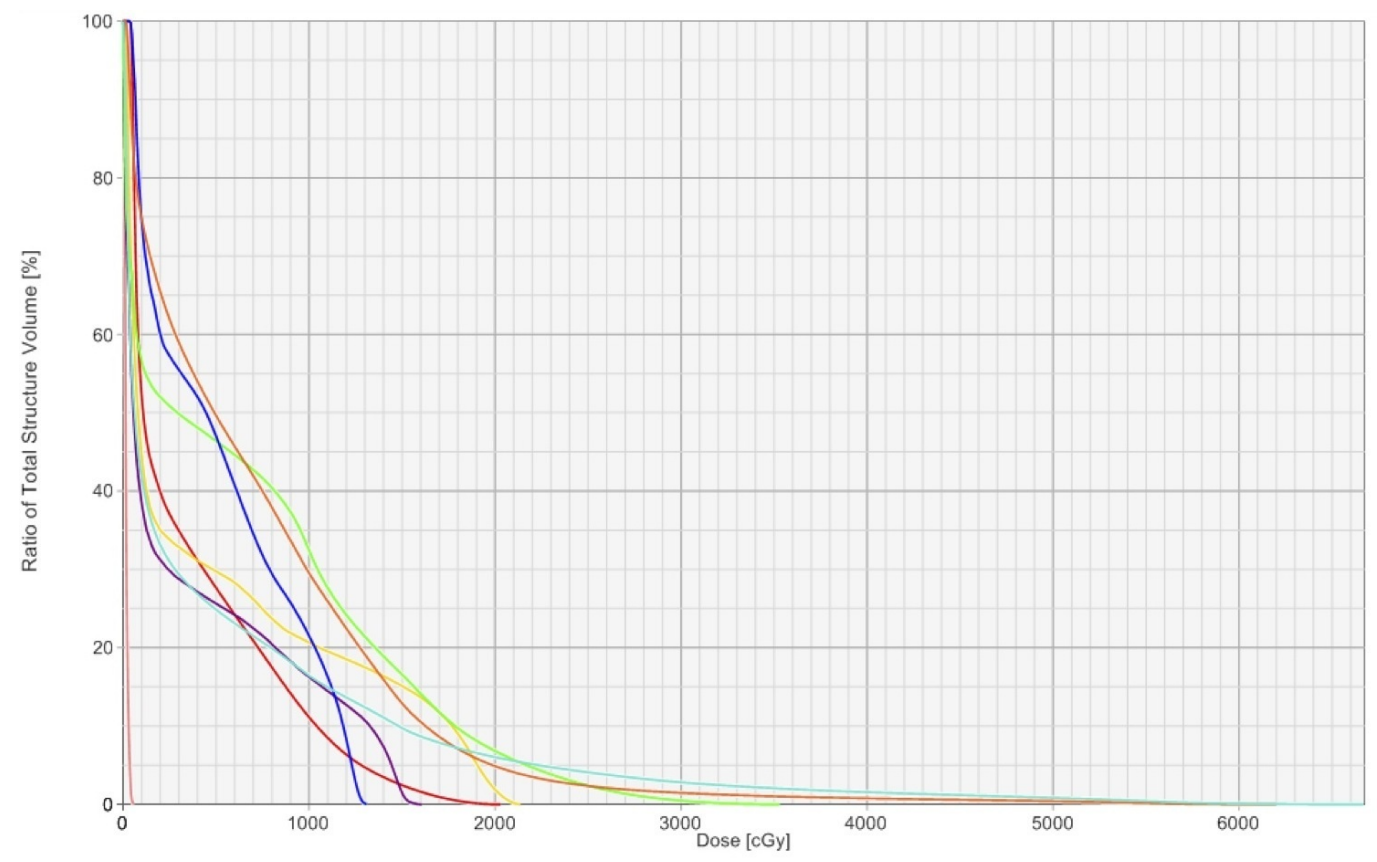

\section{FIGURE 3: Dose-volume histogram for SBRT plan sum.}

green $=$ aorta, orange $=\mathrm{D} 2 \mathrm{~cm}$, dark blue $=$ bronchial tree, yellow $=$ spinal cord, purple $=$ esophagus, light blue $=$ lungs $($ combined $)$, red $=$ pulmonary artery, pink $=$ heart

\section{Discussion}

Prior to discussion of treatment, it should be appreciated that staging synchronous or metachronous primary lung cancers requires diagnostic acumen. Several case reports underline the importance of thorough staging, to allow for appropriate treatment to be offered to patients who could be easily mistaken to have multicentric disease or intrapulmonary metastases and thereby be denied radical treatment [8]. For similar reasons, lower survival rates have been associated with a short (< 2 years) interval between detection of first and second primary tumours in metachronous lung cancer [9].

The challenge in this case lay not in the diagnosis but in the limitation of treatment options due to very poor baseline pulmonary function, secondary to severe COPD and advanced emphysema. The patient was assessed to not be a candidate for radical thoracic radiotherapy. As such, the initial proposed treatment was systemic chemotherapy, foregoing the $5.4 \%$ increase in three-year survival offered by the combined approach [1]. This was clearly suboptimal, given the low $8.9 \%$ three-year survival rate in LS-SCLC treated with chemotherapy alone; however, in light of the patient's small primary and lack of nodal disease, it was conjectured that she might do better than the population studied [1].

Although SBRT is widely used as a curative treatment for peripheral Stage I NSCLC, few studies have been published on the use of SBRT for SCLC. As SCLC is generally more radiosensitive than NSCLC, SBRT in combination with chemotherapy would seem an effective LS-SCLC treatment, particularly in patients who are not fit to undergo surgical resection or conventionally fractionated radiotherapy. A single-institution report on eight inoperable LSSCLC patients treated with SBRT (48 Gy in 4 fractions) and chemotherapy demonstrated this to be a safe and effective alternative to surgery and chemotherapy, with three-year survival and local control rates of $72 \%$ and $100 \%$, respectively, and minimal toxicity [10]. 
Further study is necessary to determine the optimal SBRT dose and fractionation schedule for treating LS-SCLC. It has been proposed that, given the relatively higher radiosensitivity of SCLC, a slightly lower radiation dose than that used to treat NSCLC may be appropriate. Furthermore, given the rapid proliferation rate of SCLC, a greater number of SBRT fractions may be of benefit. Finally, ascertaining the optimal timing of chemotherapy with SBRT, be it neoadjuvant, concurrent, or adjuvant, requires further investigation [10].

The primary literature provides better-established recommendations for treating this patient's NSCLC. For fit patients with Stage I NSCLC, surgery is considered the primary curative treatment. However, severe COPD (Global Initiative for COPD III-IV) presents an increased risk of postoperative complications. For these patients, SBRT is considered a safe alternative firstline treatment, which has been demonstrated to be non-inferior to surgery in one- and threeyear survival [11]. Furthermore, when compared to conventionally fractionated radiotherapy in Stage I NSCLC patients, SBRT has been shown to be less expensive and associated with superior local control and overall survival [12]. A poor baseline pulmonary function test, as this patient had, has been observed to not increase pulmonary toxicity or decrease overall survival in Stage I NSCLC after SBRT [13].

In considering what may have predisposed this patient to develop a second primary lung cancer, three risk factors can be identified: COPD, smoking, and SCLC. COPD has been shown to increase the risk of all subtypes of lung cancer, independent of tobacco use, with a suggested mechanism involving genetic changes, cytokines, and cell cycle dysregulation in the presence of proteinases produced by immune cells [14]. Smoking has been hypothesized to increase the risk of synchronous multiple primary lung cancers by inducing a mutation in the p53 tumour suppressor gene; $\mathrm{p} 53$ status was not assessed in this case [15].

In patients with SCLC, studies have demonstrated that smoking cessation before or at the time of initial treatment results in a 3- to 4-fold reduction in the relative risk of development of a second primary lung cancer [3]. Evidently smoking cessation should be a component of such patients' management to decrease their risk of developing a second primary lung cancer, associated with COPD or with smoking itself. Although post-treatment surveillance practices vary and their survival benefit remains questionable, in such a population with ongoing risk factors of COPD and smoking, close surveillance seems warranted, both for monitoring for recurrence of the treated primary and for screening for potentially curable metachronous cancers [9].

\section{Conclusions}

A case of metachronous SCLC and NSCLC has been presented here in a patient with an insufficient pulmonary function to tolerate surgical resection or conventionally fractionated thoracic radiotherapy. The use of consolidation SBRT after chemotherapy to achieve a complete radiologic response was demonstrated in the treatment of LS-SCLC, although it was noted that further research is required to define SBRT dose, fractionation schedule, and timing with chemotherapy in this setting. Careful staging of patients with multiple pulmonary nodules, promotion of smoking cessation to reduce the risk of developing a second primary lung cancer, and appropriate post-treatment surveillance were recognized as important components of management.

\section{Additional Information}

\section{Disclosures}

Human subjects: Consent was obtained by all participants in this study. Conflicts of interest: In compliance with the ICMJE uniform disclosure form, all authors declare the following: 
Payment/services info: All authors have declared that no financial support was received from any organization for the submitted work. Financial relationships: All authors have declared that they have no financial relationships at present or within the previous three years with any organizations that might have an interest in the submitted work. Other relationships: All authors have declared that there are no other relationships or activities that could appear to have influenced the submitted work.

\section{References}

1. Pignon JP, Arriagada R, Ihde DC, Johnson DH, Perry MC, Souhami RL, Brodin O, Joss RA, Kies MS, Lebeau B, Onoshi T, Østerlind K, Tattersall MHN, Wagner H: A meta-analysis of thoracic radiotherapy for small-cell lung cancer. New Engl J Med. 1992, 327:1618-24.

10.1056/NEJM199212033272302

2. Vallières E, Shepherd FA, Crowley J, Van Houtte P, Postmus PE, Carney D, Chansky K, Shaikh Z, Goldstraw P; International Association for the Study of Lung Cancer International Staging Committee and Participating Institutions: The IASLC Lung Cancer Staging Project: proposals regarding the relevance of TNM in the pathologic staging of small cell lung cancer in the forthcoming (seventh) edition of the TNM classification for lung cancer. J Thorac Oncol. 2009, 4:1049-59. 10.1097/JTO.0b013e3181b27799

3. Johnson BE: Second lung cancers in patients after treatment for an initial lung cancer . J Natl Cancer Inst. 1998, 90:1335-45. 10.1093/jnci/90.18.1335

4. Chang MY, Sugarbaker DJ: Surgery for early stage non-small cell lung cancer . Semin Surg Oncol. 2003, 21:74-84. 10.1002/ssu.10024

5. Bradley J: A review of radiation dose escalation trials for non-small cell lung cancer within the Radiation Therapy Oncology Group. Semin Surg Oncol. 2005, 32:S111-13.

10.1053/j.seminoncol.2005.03.020

6. Crabtree TD, Denlinger CE, Meyers BF, El Naqa I, Zoole J, Krupnick AS, Kreisel D, Patterson GA, Bradley JD: Stereotactic body radiation therapy versus surgical resection for stage I nonsmall cell lung cancer. J Thorac Cardiovasc Surg. 2010, 140:377-86.

10.1016/j.jtcvs.2009.12.054

7. Baumann P, Nyman J, Hoyer M, Wennberg B, Gagliardi G, Lax I, Drugge N, Ekberg L, Friesland S, Johansson KA, Lund JA, Morhed E, Nilsson K, Levin N, Paludan M, Sederholm C, Traberg A, Wittgren L, Lewensohn R: Outcome in a prospective phase II trial of medically inoperable stage I non-small-cell lung cancer patients treated with stereotactic body radiotherapy. J Clin Oncol. 2009, 27:3290-96. 10.1200/JCO.2008.21.5681

8. Zardo P, Kruer T, Schiffmann S, Freermann S, Fischer S: Triple synchronous primary lung cancer. Asian Cardiovasc Thorac Ann. 2014, 22:865-68. 10.1177/0218492313495550

9. Loukeri AA, Kampolis CF, Ntokou A, Tsoukalas G, Syrigos K: Metachronous and synchronous primary lung cancers: diagnostic aspects, surgical treatment, and prognosis. Clin Lung Cancer. 2015, 16:15-23. 10.1016/j.cllc.2014.07.001

10. Shioyama Y, Nakamura K, Sasaki T, Ohga S, Yoshitake T, Nonoshita T, Asai K, Terashima K, Matsumoto K, Hirata H, Honda H: Clinical results of stereotactic body radiotherapy for Stage I small-cell lung cancer: a single institutional experience. J Radiat Res. 2013, 54:108-12. 10.1093/jrr/rrs075

11. Palma D, Lagerwaard F, Rodrigues G, Haasbeek C, Senan S: Curative treatment of Stage I nonsmall-cell lung cancer in patients with severe COPD: stereotactic radiotherapy outcomes and systematic review. Int J Radiat Oncol. 2012, 82:1149-56. 10.1016/j.ijrobp.2011.03.005

12. Lanni TB Jr, Grills IS, Kestin LL, Robertson JM: Stereotactic radiotherapy reduces treatment cost while improving overall survival and local control over standard fractionated radiation therapy for medically inoperable non-small-cell lung cancer. Am J Clin Oncol. 2011, 34:49498. 10.1097/COC.0b013e3181ec63ae

13. Stanic S, Paulus R, Timmerman RD, Michalski JM, Barriger RB, Bezjak A, Videtic GM, Bradley $\mathrm{J}$ : No clinically significant changes in pulmonary function following stereotactic body radiation therapy for early- stage peripheral non-small cell lung cancer: an analysis of RTOG 0236. Int J Radiat Oncol. 2014, 88:1092-99. 10.1016/j.ijrobp.2013.12.050

14. Houghton AM: Mechanistic links between COPD and lung cancer . Nat Rev Cancer. 2013, 13:233-45. 10.1038/nrc3477 


\section{Cureus}

15. Lin CC, Chian CF, Perng WC, Cheng MF: Synchronous double primary lung cancers via p53 pathway induced by heavy smoking. Ann Saudi Med. 2010, 30:236-38. 10.4103/02564947.62837 